\title{
INTEGRAÇÃO TERRITORIAL NO MERCOSUL: O CASO DA IIRSA/COSIPLAN
}

\section{Territorial integration in MERCOSUR: the IIRSA/ COSIPLAN case}

\author{
Vitor Hélio Pereira de Souza \\ Universidade Federal de Santa Catarina, Florianópolis, Santa Catarina, Brasil \\ vitorgedri@hotmail.com
}

Artigo recebido em 08/03/2014 e aceito para publicação em 12/12/2014

RESUMO: No final do século XX, com a abertura econômica e a ampliação dos "circuitos espaciais de produção", os países passaram a expandir, cada vez mais, sua participação no comércio exterior, utilizando-se do regionalismo enquanto forma de resguardar-se da competitividade internacional. Por outro lado, acentuouse a busca por novos mercados, além da diversificação de parceiros comerciais, visando à redução dos riscos provenientes das crises de demanda. Nessa conjuntura, foram dados os primeiros passos do que seria futuramente o MERCOSUL, que conquistou importante representatividade nas balanças comerciais dos países da região. Por sua vez, essa ascendência das transações comerciais intrarregionais nas últimas décadas revelou um descompasso entre o crescimento dos fluxos de mercadoria e os insuficientes investimentos em infraestrutura realizados no âmbito do Cone Sul. Foi somente ao adentrar o século XXI, com o lançamento da IIRSA/COSIPLAN, que antigas obras propostas para a região foram viabilizadas. Palavras-chave: MERCOSUL. Infraestrutura. Transporte. Integração Territorial. IIRSA/COSIPLAN.

ABSTRACT: In the late twentieth century, with economic liberalization and expansion of "spatial circuits of production" countries have been expanding, increasingly, their participation in international trade using regionalism as a mean to guard against international competitiveness. On the other hand, sharpened up the search for new markets and diversification of trade partners, in order to reduce risks from the crisis of demand. At this juncture, were the first steps of what would eventually Mercosur, which got major importance in trade balances of countries of the region. In turn, this ascendancy of intraregional trade transactions in recent decades, has revealed a mismatch between the growth in the flow of merchandise and insufficient infrastructure investments undertaken within the Southern Cone. Already when entering the twenty-first century, with the launch of IIRSA / COSIPLAN some old works proposed for the region would be made possible.

Keywords: Mercosur. Infrastructure. Transport. Regional Integration. IIRSA/COSIPLAN. 


\section{INTRODUÇÃO}

A partir da década de 1980, uma série de tratados de "Preferências Tarifárias Regionais" e "Acordos de Complementação Econômica" foram instituídos entre a Argentina e o Brasil, resultando no estabelecimento de importante complementação da economia de ambos os países. Na década seguinte, com a constituição do Mercado Comum do Sul (MERCOSUL), essas relações expandiramse incorporando Paraguai, Uruguai e demais países associados, resultando na constituição de um importante bloco regional.

Entre progressos e retrocessos, o comércio exterior na região conquistou considerável representatividade nas balanças comerciais dos países membros, haja vista que, para o período 1990 a 2011, as importações intrabloco cresceram quase treze vezes, ampliando-se de US\$ 4.052 milhões para US\$52.456 milhões; por sua vez, as exportações cresceram também quase treze vezes, expandindo-se de US\$ 4.228 milhões para US\$ 53.785 milhões. Esse aumento das transações comerciais intrarregionais nas últimas décadas revelou fragilidades já existentes entre os países do Cone Sul. Esse foi o caso do descompasso entre o crescimento dos fluxos de mercadoria e os insuficientes investimentos em infraestrutura realizados na região.

Vale lembrar que a busca por maior fluidez para a circulação de mercadorias na região não é novidade. A contiguidade territorial entre os países que compõem o MERCOSUL, antes mesmo da criação institucional do bloco econômico, influenciou no estabelecimento de "interações espaciais" (SILVEIRA, COCCO, 2010) entre as primeiras áreas ocupadas na porção austral do continente sul-americano. Esse fato exigiu no decorrer dos anos a substituição dos meios naturais de comunicação pelo estabelecimento de grandes obras de engenharia que gradativamente estabeleceram a consolidação, ainda que incompleta, de uma rede de transporte no Cone Sul.

Tal fato pode ser explicado devido à intenção dos países em fomentar o comércio intrarregional. Desta maneira, já no ano de 1977, os governos dos países da região em parceria definiram a "Rede Fundamental de Transporte do Cone Sul", um conjunto de obras identificadas como essenciais para ampliação da fluidez territorial sul-americana, com destaque para a porção austral do continente. Já nas próximas décadas outros estudos foram realizados, salientando as novas demandas por transporte, no entanto poucos projetos tornaram-se realidade até meados do século XXI.

Foi somente com a Iniciativa para a Integração da Infraestrutura Regional Sul-Americana (IIRSA) no ano 2000 que algumas das antigas demandas por transporte, anteriormente identificadas nos projetos elaborados a partir da década de 1970, saíram do papel, vide Valenciano (1980), Sant'Anna (1997), Luraschi (2000) entre outros. Neste ínterim, este trabalho adotou enquanto procedimento metodológico a análise de fonte de dados secundárias, como a evolução dos Portfólios e da Agenda de Implementação Concensuada da IIRSA para o período 2005-2010; assim como o Portfólio do COSIPLAN e a Agenda de Projetos Prioritários (API), para o período de 2011-2016, entre outros documentos analisados, com enfoque para a região do MERCOSUL, recorte territorial equivalente à região do Cone Sul, uma vez que, a Venezuela ainda não havia sido incorporada ao bloco.

Para tanto, este artigo encontra-se organizado em três tópicos. Na primeira parte, apresentamos a IIRSA e sua evolução para COSIPLAN, a partir do Eixo de Integração e Desenvolvimento (EID) MERCOSUL-Chile, que deverá abarcar diretamente a região do MERCOSUL. Na sequência, apresentamos as obras delimitadas na Agenda de Implementação Concensuada (AIC) e na Agenda de Projetos Prioritários (API) para o EID MERCOSUL-Chile, documento que já motivou algumas análises acadêmicas. E, por fim, buscamos destacar a extensa lista de obras delimitadas nos Portfólios da IIRSA e do COSIPLAN para o EID MERCOSUL-Chile, um documento interessante, porém ainda pouco analisado pela academia.

Logo, nesta trajetória julgamos pertinente acercarmo-nos de algumas questões referentes aos projetos da IIRSA/COSIPLAN destinados ao MERCOSUL: Quais regiões devem ser contempladas com investimentos? Quais setores devem receber maiores investimentos? No caso do setor de transporte, 
quais modais devem ser favorecidos? Quais tipos de obras devem ser realizados? Enfim, qual integração territorial vem sendo promovida na região?

\section{A IIRSA/COSIPLAN E O MERCOSUL}

Na segunda metade do século XX, com a retomada dos ideais integracionistas na América Latina, houve alguns estudos que tiveram a questão territorial enquanto enfoque, demonstrando as deficiências das infraestruturas de integração existentes. Porém, grandes partes desses planos não se tornariam realidade até meados do ano 2000, momento em que foi lançada a IIRSA.

Tal iniciativa, enquanto um plano de integração para toda a América do Sul, regionalizou o continente por meio da seleção de 10 Eixos de Integração e Desenvolvimento (EID) Andino, Andino do Sul, Capricórnio, Hidrovia Paraguai-Paraná, Amazonas, Escudo Guianês, do Sul, Interoceânico Central, Peru-Brasil-Bolívia e MERCOSUL-Chile, isto é, grandes obras de infraestrutura com capacidade de articular territórios. Já considerando as diferenças regionais existentes, foi realizada a distinção entre EID: Emergentes e Com Dinâmica de Integração Pré-estabelecidos.

Neste ínterim, os países pertencentes ao MERCOSUL foram compreendidos pelo EID (Com Dinâmica de Integração Pré-estabelecida) MERCOSUL-Chile, o que retoma, de certa maneira, as aspirações do Barão de Rio Branco em fortalecer a união entre as três maiores economias do Cone Sul: Argentina, Brasil e Chile (ABC), atualmente de uma forma mais robusta, incluindo o Paraguai, Uruguai, Venezuela e países associados, além de abarcados indiretamente também pelos EIDs Andino, Andino do Sul, Capricórnio, Hidrovia Paraguai-Paraná.

O EID MERCOSUL-Chile apresenta um recorte espacial que abrange uma área de influência de aproximadamente $3.216 .277 \mathrm{~km}^{2}$, número equivalente a $25,46 \%$ da superfície total dos países membros. Embora não pareça relevante a extensão territorial apontada, salientamos que nessa área encontram-se os núcleos urbanos com maior concentração populacional de cada país, com 140.342.308 de habitantes, isto é, aproximadamente
$54,89 \%$ da população total dos países, conforme dados referentes ao ano de 2008.

Entre as principais cidades destacam-se, no caso argentino, a Cidade Autônoma de Buenos Aires (CABA), Córdoba/CB e Mendoza/MZ; no Brasil, toda a Região Sul e parte da Região Sudeste com as capitais Porto Alegre/RS, Florianópolis/SC, Curitiba/PR, São Paulo/SP e Belo Horizonte/MG; no Paraguai, a Região Oriental; no Chile, quase a totalidade do país e no Uruguai todo o país.

Consequentemente, devido à dinâmica econômica existente nessa área, ocorre a concentração dos principais portos de cada país, como, no caso brasileiro, os portos de Santos, além do porto de Paranaguá, São Francisco e Porto Alegre; no caso argentino, os portos de Corrientes, Diamente, San Lourenzo e Quequén; no Paraguai, o porto de Assunção; no Uruguai, o porto de Montevidéu e no Chile, o porto de Valparaíso e Coquimbo.

Existe nessa área, também, uma concentração de importantes rotas de exportação de mercadorias, no âmbito intrarregional, mediante a existência de diversos postos aduaneiros de fronteiras, a saber: no Brasil, Foz do Iguaçu, D. Cerqueira e Uruguaiana; na Argentina, San Javier, Paso de Los Libres, Puerto Unzué, Agua Negra, Picas Negra, Cristo Redentor; no Paraguai, Ciudad del Este; no Uruguai, Chuy, Santana, Río Branco e no Chile, Agua Negra, Cristo Redentor e Pehuenche (Vide Tabela 1). 
Tabela 1: Superfície, população, principais cidades, passagens de fronteira e portos marítimos e fluviais no EID MERCOSUL-Chile.

\begin{tabular}{|c|c|c|c|c|c|}
\hline $\begin{array}{l}\text { Países Unidades } \\
\text { Territoriais }\end{array}$ & $\begin{array}{l}\text { Superfície } \\
\mathrm{Km}^{2}\end{array}$ & $\begin{array}{l}\text { População } \\
\text { Hab. } 2008\end{array}$ & $\begin{array}{l}\text { Principais } \\
\text { Cidades }\end{array}$ & $\begin{array}{l}\text { Passagens de } \\
\text { Fronteira }\end{array}$ & $\begin{array}{l}\text { Portos } \\
\text { marítimos e } \\
\text { fluviais }\end{array}$ \\
\hline \multicolumn{6}{|l|}{ Argentina } \\
\hline Total & 27.780 .400 & 39.745 .613 & & & \\
\hline Misiones & 29.801 & 1.077 .987 & Posadas & San Javier & \\
\hline Corrientes & 88.199 & 1.013 .443 & Corrrientes & $\begin{array}{l}\text { Paso de Los } \\
\text { Libres }\end{array}$ & Corrientes \\
\hline Entre Ríos & 78.781 & 1.255 .787 & Paraná & Puerto Unzué & Diamante \\
\hline Santa Fé & 133.007 & 3.242 .551 & Rosario & & San Lorenzo \\
\hline Córdoba & 165.321 & 3.340 .041 & Córdoba & & \\
\hline San Luis & 76.748 & 437.544 & San Luis & & \\
\hline San Juan & 89.651 & 695.640 & San Juan & Agua Negra & \\
\hline La Rioja & 89.680 & 341.207 & La Rioja & Picas Negras & \\
\hline Buenos Aires & \begin{tabular}{|l|}
307.751 \\
\end{tabular} & 15.052 .177 & La Plata & & Quequén \\
\hline La Pampa & \begin{tabular}{|l|}
143.440 \\
\end{tabular} & 333.550 & La Pampa & & \\
\hline Mendoza & 148.827 & 1.729 .660 & Mendoza & $\begin{array}{l}\text { Cristo } \\
\text { Redentor }\end{array}$ & \\
\hline Área de Influência & 1.351 .226 & 31.562 .168 & & & \\
\hline \multicolumn{6}{|c|}{ Brasil } \\
\hline Total & 8.514 .877 & 189.612 .814 & & & \\
\hline Minas Gerais & 586.528 & 19.850 .072 & Belo Horizonte & & \\
\hline São Paulo & 248.209 & 41.011 .635 & São Paulo & & Santos \\
\hline Paraná & 199.315 & 10.509 .169 & Curitiba & Foz do Iguaçu & Paranaguá \\
\hline Santa Catarina & 95.346 & 6.052 .587 & Florianópolis & D. Cerqueira & S. Francisco \\
\hline $\begin{array}{l}\text { Rio Grande do } \\
\text { Sul }\end{array}$ & 281.748 & 10.855 .214 & Porto Alegre & Uruguaiana & Porto Alegre \\
\hline Area de Influência & 1.411 .146 & 88.359 .677 & & & \\
\hline \multicolumn{6}{|l|}{ Paraguai } \\
\hline Total & 406.752 & 6.230 .000 & & & \\
\hline Região Oriental & 159.827 & 6.064 .411 & Ciudad del Este & Ciudad del Este & Assunção \\
\hline Área de Influência & 159.827 & 6.064 .411 & & & \\
\hline \multicolumn{6}{|c|}{ Uruguai } \\
\hline Total & 175.016 & 3.334 .052 & Montevideo & $\begin{array}{l}\text { Chuy, Santana, } \\
\text { Río Branco }\end{array}$ & Montevideo \\
\hline Área de influência & \begin{tabular}{|l|}
175.016 \\
\end{tabular} & 3.334 .052 & & & \\
\hline \multicolumn{6}{|l|}{ Chile } \\
\hline Total & \begin{tabular}{|l|l|}
756.102 \\
\end{tabular} & 16.763 .470 & & & \\
\hline $\begin{array}{l}\text { IV Região } \\
\text { Coquimbo }\end{array}$ & 40.580 & 698.000 & La Serena & Agua Negra & Coquimbo \\
\hline $\begin{array}{l}\text { V Região } \\
\text { Valparaíso }\end{array}$ & 16.396 & 1.720 .600 & Valparaíso & $\begin{array}{l}\text { Cristo } \\
\text { Redentor }\end{array}$ & Valparaíso \\
\hline $\begin{array}{l}\text { Região } \\
\text { Metropolitana }\end{array}$ & 15.403 & 6.745 .700 & Santiago & & S. Antonio \\
\hline $\begin{array}{l}\text { VI Região } \\
\text { O'Higgins }\end{array}$ & 16.387 & 866.200 & Rancagua & & \\
\hline VII Região Maule & 30.296 & 991.500 & Talca & Pehuenche & \\
\hline Área de Influência & 119.062 & 11.022 .000 & & & \\
\hline Total dos países & 12.458 .131 & 255.685 .949 & & & \\
\hline $\begin{array}{l}\text { Total área de } \\
\text { influencia }\end{array}$ & 3.216 .277 & 140.342 .308 & & & \\
\hline
\end{tabular}


Além do mais, essa área é responsável por grande parte do PIB (Produto Interno Bruto) gerado em cada país, havendo a presença de atividades econômicas diversificadas, como as indústrias de couro e têxteis; agrícolas e agroindustrial; agropecuárias e graneleiras; indústria de veículos e material de transporte; indústria aeronáutica; serviços industriais metalúrgicos, metal-mecânica; turismo; química; celulose, madeira e papel; hidrocarbonetos; máquinas agrícolas, indústria vitivinícola (produção de vinhos); produção mineral metálica; recursos florestais; produtos químicos e indústria manufatureira (IIRSA, 2010).

Sendo assim, em novembro de 2004, foi selecionado, em meio ao Portfólio da IIRSA, um grupo constituído por 31 obras, que vieram a compor a Agenda de Implementação Concensuada (AIC) para o período de 2005-2010. Já no ano de 2011, com o Conselho Sul-Americano de Infraestrutura e Planejamento (COSIPLAN) essa lista de projetos principais foi atualizada, recebendo o nome de Agenda de Projetos Prioritários (API), com obras delimitadas para o período de 2011-2016.

Logo, esse pacote de obras passou a funcionar enquanto vitrine da iniciativa, ganhando destaque enquanto marketing governamental do projeto e tornando-se objeto de grande parte das análises acadêmicas. Tal opção é compreensível e justificável, uma vez que se trata geralmente de grandes projetos determinados como estratégicos para promover a integração regional, tornando-se um recorte interessante para iniciar a discussão sobre as obras selecionadas na AIC/ API destinadas ao EID MERCOSUL-Chile.

\section{AS OBRAS SELECIONADAS NA AIC/ API DESTINADAS AO EID MERCOSUL-CHILE}

Nessa lista de obras prioritárias, o EID MERCOSUL-Chile foi compreendido por meio de sete projetos, sendo cinco rodoviários, um ferroviário e um gasoduto. Tais obras totalizavam, no ano de 2005 , investimentos estimados no valor de US\$ 2.882 milhões, havendo três projetos em execução, três projetos em pré-execução e um projeto em licitação. Prontamente, no ano de 2010, momento em que foi divulgado o último informe da carteira de projetos, os custos totais das obras haviam evoluído para US\$ 8.135 milhões e nenhuma obra ainda tinha sido concluída (Vide Tabela 2). 
Tabela 2: Projetos do EID MERCOSUL-Chile delimitados para a AIC referente ao período de 2005 a 2010 (em milhões de US\$).

\begin{tabular}{|c|c|c|c|c|c|c|c|c|}
\hline \multicolumn{9}{|c|}{ MERCOSUL-CHILE } \\
\hline $\mathrm{N}^{0}$ & Obras & 2005 & 2006 & 2007 & 2008 & 2009 & 2010 & Países \\
\hline 1 & Duplicação da rota 14 & 370,00 & --- & --- & 780,00 & --- & ----- & $\begin{array}{l}\mathrm{AR} \\
(\mathrm{BR})\end{array}$ \\
\hline 2 & $\begin{array}{l}\text { Adequação do corredor Rio } \\
\text { Branco- Montevideo- Colonia- } \\
\text { Nueva Palmira }\end{array}$ & 163,00 & 176,80 & --- & 266,40 & 247,50 & 234,0 & $\begin{array}{l}\text { UY } \\
(\mathrm{AR}- \\
\text { BR) }\end{array}$ \\
\hline 3 & $\begin{array}{llr}\text { Construção da } & \text { Ponte } \\
\text { Internacional Jaguarão } & - \text { Rio } \\
\text { Branco } & \\
\end{array}$ & 12,00 & ----- & --- & 24,60 & 35,00 & - & BR-UY \\
\hline 4 & $\begin{array}{lr}\text { Duplicação do } & \text { Tramo } \\
\text { Palhoça- Osorio } & \text { (Rodovia } \\
\text { MERCOSUL) } & \end{array}$ & 800,00 & ---- & 1200,0 & --- & 989,00 & 700,0 & $\begin{array}{l}\text { BR } \\
\text { (AR- } \\
\text { UY) }\end{array}$ \\
\hline 5 & $\begin{array}{ll}\text { Projeto Ferroviario } & \text { Los } \\
\text { Andes- Mendoza } & \end{array}$ & 251,00 & ---- & ---- & 3000,00 & 3000,00 & $5.100,0$ & AR-CH \\
\hline 6 & $\begin{array}{l}\text { Rota Internacional CH } 60 \\
\text { (Setor Valparaíso- Los Andes) }\end{array}$ & 286,00 & ---- & ---- & ----- & 280,00 & 286,0 & $\begin{array}{l}\mathrm{CH} \\
(\mathrm{AR})\end{array}$ \\
\hline 7 & $\begin{array}{lll}\text { Gasoduto do Nordeste } \\
\text { Argentino }\end{array}$ & $1.000,0$ & & ---- & 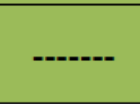 & --- & ----- & $\begin{array}{l}\mathrm{AR} \\
(\mathrm{BO})\end{array}$ \\
\hline Tot & & 2.882 & $2.895,8$ & $3.295,8$ & 6.557 & $6.331,5$ & 8.135 & \\
\hline & Perfil & xecução & & Licitaçã & & cução & Col & lído \\
\hline
\end{tabular}

Fonte: IIRSA - Agenda de Implementación Consensuada, 2005, 2006, 2007, 2008, 2009, 2010.

No território brasileiro, o principal projeto delimitado para o eixo foi a ampliação e duplicação da BR-101 entre o município de Palhoça/SC e Osório/ RS, trata-se de uma extensão de $337,5 \mathrm{~km}$ de rodovia (249 km no Estado de Santa Catarina e 88,5 km do Estado do Rio Grande do Sul). O projeto contou também com a restauração de pontes, construção de túneis, viadutos, passagens interiores e passarelas, a fim de reduzir tempo e custo de viagem pelo trajeto, além de proporcionar melhor segurança para a rota.

O Brasil, em parceria com o Uruguai, foi responsável igualmente pela construção da segunda ponte internacional sobre o rio Jaguarão, a Ponte Internacional Jaguarão-Rio Branco, que ligará a BR116 e a Rota 26 UR. Essa obra objetiva desviar o tráfego da rota Chuí/Chuy para preservar a Reserva Ecológica do Taim e restringir os fluxos de carga no trecho rodoviário Pelotas/Rio Grande (BR 329/RS), além de, posteriormente, viabilizar a base para um futuro plano de ordenamento territorial para as cidades fronteiriças de Jaguarão (BR) e Rio Branco (UR).

Por outro lado, a construção da Ponte Internacional Jaguarão-Rio Branco deverá complementar o projeto levado a cargo pelo governo uruguaio de "adequação do corredor Rio BrancoMontevidéu-Colônia-Nova Palmira", que possibilitará melhor integração entre as cidades de São Paulo, Montevidéu, Buenos Aires, Santiago do Chile e Valparaíso, podendo triplicar o fluxo de mercadorias para o trajeto até o ano de 2015.

Já no território argentino, deverá ocorrer a duplicação (e demais obras auxiliares) da Rota 14, de modo a ampliar a capacidade operacional da estrada, buscando facilitar a circulação entre as cidades fronteiriças de Uruguaiana (BR), Paso de Los Libres (AR), a cidade de Frey Bento (UR) e Gualeguaychú (AR), importantes rotas de acesso de mercadorias provenientes do Brasil e do Uruguai, com destino à 
Região Metropolitana de Buenos Aires.

No Chile e na Argentina destaca-se o "Projeto Ferroviário Andes-Mendonza" que interligará Luján de Cuyo, na província de Mendoza (AR), com Los Andes na V Región $(\mathrm{CH})$, que deverá contar também com a construção de 30 a $50 \mathrm{~km}$ de túnel, a 2.500 metros acima do nível do mar, além da instalação de estações multimodais nas cabeceiras do túnel que possibilitará alternativa ao "Sistema Cristo Redentor" (rodovia que interliga a província de Mendoza-AR e Los Andes-CH), a qual poderá chegar a sua saturação em 2015, além de permitir alternativa à rota que fica intransitável aproximadamente 45 dias ao longo do ano, devido às nevascas.

Tal projeto, por sua vez, complementará a ampliação das rodovias da Rota Internacional $60 \mathrm{CH}$ (Rota Transandina), a qual tem início na fronteira entre Chile e Argentina, nas proximidades do túnel Cristo Redentor e estende-se até o porto de Valparaíso, cuja intenção foi elevar a capacidade e reduzir o tempo de circulação no trajeto. Segundo estimativas, nesse trecho percorrem cinco milhões de toneladas de mercadorias anualmente advindas dos países do MERCOSUL.

Por fim, mas não menos importante, o projeto Gasoduto do Nordeste Argentino (GNEA) deverá percorrer $1500 \mathrm{~km}$, perpassando pelas províncias de Salta, Formosa, Chaco, Misiones, Corrientes, Entre Ríos e Santa Fé, possibilitando a interconexão das reservas de gás do norte argentino e da Bolívia, com o Sistema Nacional Interconectado de Gasoductos Troncales de Argentina, além de permitir a implantação de obras complementárias de transmissão de energia e dados. Destarte, tal obra poderá assegurar o abastecimento de gás natural para a Região Nordeste da Argentina, permitindo diversos usos, como o residencial, industrial, agroindustrial, assim como o abastecimento de veículos reduzindo a dependência do país aos combustíveis derivados de petróleo, cujos preços sofrem maior influência do mercado internacional.

Em relação ao andamento dos projetos, devido ao fato de grande parte das obras serem destinadas ao modal rodoviário, alguns trechos das mesmas já foram inaugurados, porém deverá haver atraso na conclusão dos projetos. Esse é o caso das obras realizadas na BR-101, ou seja, uma obra que dura mais de dez anos e que apresenta muitos trechos concluídos, porém algumas das principais obras, até o presente momento, começaram recentemente, como a ponte rodoferroviária de Laguna/SC que tem entrega prevista para o ano de 2015, e o túnel do Morro dos Cavalos (município de Palhoça/SC), que deve ser finalizado em 2017.

Ademais, as áreas próximas às principais cidades que a rodovia possibilita acesso - como Curitiba, Joinville, Itajaí e Florianópolis - apresentam pontos saturados, uma vez que nesses trechos da rodovia os fluxos comerciais de longa distância disputam espaço com os fluxos de passageiros inter e intra-urbanos, tornando-se claro o caráter paliativo ainda que necessário da ampliação da via.

Outro exemplo é a Duplicação da Rota 14, que deveria ser concluída em sua totalidade no final do ano 2012, entretanto teve seu término somente no primeiro semestre de 2013; assim como o corredor Rio Branco- Montevideo-Colonia-Nueva Palmira, que apresentava até o primeiro semestre de 2013 um trecho de obras concluído e outros quatro em execução; além da Rota Internacional CH 60, com estimativa inicial para conclusão das obras até o final do ano de 2013.

No entanto, os atrasos mais emblemáticos foram do Projeto Ferroviário Los Andes-Mendoza, que no final de 2012 estava em fase de estudos de viabilidade técnica, econômica e financeira, os quais apontam para a construção de um túnel de uma via para o ano de 2020. Por outro lado, obras como Ponte Internacional Jaguarão - Rio Branco e o Gasoduto do Nordeste Argentino (GNEA), também com estudos incompletos, tiveram seu prazo para o início das obras prorrogado.

Já com relação à UNASUL (União de Nações Sul-Americanas), a partir do ano de 2011, ocorreu um rearranjo institucional visível na coordenação das iniciativas de integração em âmbito continental e a IIRSA foi incorporada enquanto foro técnico à COSIPLAN. Essa nova instituição subordinada à UNASUL, ao congregar em grande parte a metodologia da antiga iniciativa, resultou em poucas mudanças na maneira de conduzir os projetos de infraestrutura, ainda que tenha implicado na redução da influência dos órgãos financiadores do projeto BID (Banco Interamericano de Desenvolvimento), CAF 
(Corporação Andina de Fomento) e FONPLATA (Fundo Financeiro para o Desenvolvimento da Bacia do Prata) nas diretrizes adotadas pela iniciativa.

Sendo assim, de modo similar à antiga agenda, as obras selecionadas na API destinadas ao EID MERCOSUL-Chile foram sete: um gasoduto e uma ponte (trata-se das mesmas obras apresentada na AIC para o período de 2005 a 2010), uma obra de transporte multimodal, uma ferroviária (esse projeto é dividido em duas obras), um posto de fronteira aduaneiro e um túnel, totalizando investimentos iniciais estimados em US\$ 2.218 milhões (Vide Tabela 3).

Tabela 3: Projetos do EID MERCOSUL-Chile delimitados para a API, referente ao período de 2011 a 2016 (em milhões de US\$).

\begin{tabular}{|c|c|c|c|c|c|}
\hline \multirow[t]{2}{*}{$\mathrm{N}^{0}$} & \multirow[t]{2}{*}{ Obras } & \multirow[t]{2}{*}{ Investimentos } & \multirow[t]{2}{*}{ Países } & \multicolumn{2}{|c|}{ Previsão } \\
\hline & & & & Início & Conclusão \\
\hline 1. & Gasoduto do Nordeste Argentino & $1.000,0$ & $\mathrm{AR} / \mathrm{BO}$ & 2013 & 2014 \\
\hline 2. & $\begin{array}{l}\text { Construção da Ponte Internacional Jaguarão Rio } \\
\text { Branco }\end{array}$ & 65,0 & $\mathrm{BR} / \mathrm{UR}$ & 2012 & 2014 \\
\hline 3. & $\begin{array}{l}\text { Transporte Multimodal no Sistema Laguna } \\
\text { Merín e Lagoa dos Patos }\end{array}$ & 100,0 & BR/UR & 2012 & 2014 \\
\hline 4. & $\begin{array}{l}\text { Corredor Ferroviário Montevideo-Cacequí: } \\
\text { Recondicionamento da Ferrovia entre } \\
\text { Montevidéu e Rivera }\end{array}$ & 100,0 & UR & 2012 & 2014 \\
\hline 5. & $\begin{array}{l}\text { Corredor ferroviário Montevidéu-Cacequí: } \\
\text { Adequação Ferroviária da Bitola Brasileira } \\
\text { Rivera Santana do Livramento Cacequí }\end{array}$ & 96,0 & BR-UR & 2011 & 2012 \\
\hline 6. & $\begin{array}{l}\text { Otimização do Sistema Paso de Fronteira Cristo } \\
\text { Redentor }\end{array}$ & 7,0 & $\mathrm{AR} / \mathrm{CH}$ & 2012 & 2014 \\
\hline 7. & Túnel Binacional Água Negra & 850,0 & $\mathrm{AR} / \mathrm{CH}$ & 2014 & 2016 \\
\hline \multicolumn{2}{|c|}{ Total } & $2.218,0$ & & & \\
\hline \multicolumn{2}{|c|}{ LEGENDA } & n Licitação & Execuçã & & oncluído \\
\hline
\end{tabular}

Fonte: COSIPLAN: Agenda de Projetos Prioritários de Integração, 2011.

Como se pode constatar, alguns dos projetos que estavam na AIC não foram concluídos e passaram a fazer parte da API; esse foi o caso do Gasoduto do Nordeste Argentino (GNEA) que, no ano de 2007, concedeu à ENARSA (Energia Argentina Sociedad Anonima), por 35 anos passível de prorrogação, a responsabilidade de construir, operar, manter, transportar e comercializar o gás natural. Em 2010, foi definido o traçado final da obra e firmado o adendo de contrato de compra-venda, celebrado entre Yacimientos Petroliferos Fiscales Bolivianos (YPFB) e a ENARSA, em que ambas as partes comprometem-se a receber quantidades crescentes de Gás Natural para o período de 2010 a 2027, tendo licitações realizadas para construção das obras no ano de 2013.
O projeto Ponte Internacional Jaguarão-Rio Branco teve seus estudos de viabilidade técnica, econômica e ambiental concluídos e referendados pela comissão mista composta por Brasil e Uruguai em 2012. No caso brasileiro, a obra foi inserida no $2^{\circ}$ Programa de Aceleração de Crescimento (PAC-2) do governo brasileiro, que poderá facilitar o acesso aos investimentos necessários para a execução do projeto que teve seu início planejado para 2012, protelado para o segundo semestre de 2014.

Ainda entre Brasil e Uruguai, os projetos de Transporte Multimodal Sistema Lagoa Mirim e Lagoa dos Patos abarcam no Uruguai a Lagoa Mirim e seus afluentes (o rio Yaguarón, o Cebollatí e o Tacurí); já no Brasil os projetos abrangem a Lagoa Mirim e seus 
afluentes (o rio Yaguarón, o canal de São Gonçalo, os canais de acesso ao porto de Rio Grande, a Lagoa dos Patos e seus alimentadores: o Rio Guaiba, Taguarí, Jacuí, dos Sinos, Gravataí, Caí e Camaquã). Posto isso, os projetos objetivam reativar o transporte lacustre para cargas e passageiros (COSIPLAN, 2011).

Para tanto, estão previstas obras de dragagem, desviamento, sinalização, elaboração de cartas náuticas eletrônicas, implantação e manutenção de réguas limimétricas, contratação de estudos e implantação de novos terminais, com destaque para terminais localizados no estado do Rio Grande do Sul, como a implantação dos terminais de cargas em São José do Norte; a ampliação dos terminais de Estrela no Rio Taquari, de Cachoeira do Sul no Rio Jacuí, de Santa Vitória do Palmar na Lagoa Mirim e em Porto Alegre na Lagoa Guaíba; e, por fim, a adequação do Porto de Pelotas no canal São Gonçalo.

Visto que se trata de uma hidrovia binacional, esta precisará, também, da criação de aduanas, regulação de migração etc. Esse é um projeto de grande interesse para ambos os países, constando na "Dirección Nacional de Hidrografía del Ministerio de Transporte y Obras Públicas" do Uruguai para o período de 2010-2014 e, no Brasil, está incluso nas obras do PAC 2.

Além do mais, Brasil e Uruguai juntaram esforços para a conclusão do corredor Ferroviário Montevidéu - Cacequí. Trata-se de um projeto estruturado composto por dois projetos individuais:

Reabilitação da Ferrovia entre Montevidéu e Rivera, visando primeiramente melhorar o nível de serviço no trecho, permitindo ampliar a velocidade de trânsito e, por conseguinte, reforçar as estruturas existentes para futuramente expandir a capacidade de carga da ferrovia para 22 toneladas;

$\checkmark$ Além disso, por se tratar de um trecho com tráfego suspenso há dez anos, deverão ser recuperados $158 \mathrm{~km}$ deferroviasentreCacequí até Santana do Livramento na fronteira com Uruguai, que consecutivamente serão integradas ao trecho Rivera-Montevidéu, buscando ampliar as interações espaciais entre os dois países, aproveitando-se que, embora as bitolas sejam diferentes (o trecho brasileiro apresenta bitola de 1,00 metro, já o uruguaio possui bitola do tipo standard com 1,435 metros), as ferrovias encontram-se em Santana do Livramento/Rivera, local que apresenta bitola mista. Dessa maneira, estão programadas a substituição de dormentes, a limpeza de cortes, o reforço de aterro e a recuperação de dez pontes.

Já a Argentina e o Chile selecionaram, como prioritária, a otimização do Sistema Posto de Fronteira Cristo Redentor, que poderá ter algumas das etapas iniciadas em 2014. Esse trajeto é estratégico para ambos os países por se tratar da principal conexão entre eles, abarcando a $V$ Región (Chile) e a província de Mendoza (Argentina), e deverá também melhorar as vias de acesso da região, assim como a operação dos Postos de Fronteira, os quais passarão a oferecer serviços logísticos completos, reduzindo o tempo de gasto com os trâmites fronteiriços.

Ademais, a rota é o principal acesso do Brasil ao mercado chileno e ao Oceano Pacífico, ocorrendo preferencialmente pelo porto de Valparaíso, que deverá ficar saturado até o ano de 2015. Dessa maneira, tornou-se estratégico descentralizar os fluxos e investir em outros portos, como San Antonio e Quinteros, ambos os projetos incluídos no Plan Estratégico Territorial Avance II: Integración Territorial Internacional do governo argentino e no documento Chile 2020: obras públicas para el desarrollo, entre outros.

Em decorrência da canalização de grande parte dos fluxos, por meio do Sistema Cristo Redentor, também tornou-se importante investir em uma rota alternativa de conexão entre Argentina e Chile. Para tanto, foi criado o projeto Túnel Binacional Água Negra, firmado pelo Tratado de Maipú entre Argentina e Chile no ano de 2009, cujo objetivo foi interligar a IV Región (Chile) e a província de San Juan (Argentina), acarretando, também, em um trajeto alternativo para o fortalecimento do corredor bioceânico Porto Alegre (Brasil) ao Porto de Coquimbo (Chile). Por sua vez, a obra consiste na implantação de um túnel que permitirá aos veículos 
evitar áreas de difícil circulação e com elevada precipitação, bem como a pavimentação de trechos sem calçamento. Em decorrência da execução dessa obra, deverão ser realizados investimentos para a melhoria das Rotas 41 no Chile e 150 na Argentina, além de investimentos para facilitar o acesso ao porto na cidade de Coquimbo.

Ora, como se pode constatar, os projetos apresentados na AIC para o período de 2005 a 2010 e na API para o período de 2011 a 2016 visam satisfazer demandas antigas por maior fluidez territorial. Ou seja, grande parte das obras apresentadas trata de recuperação ou ampliação de infraestruturas existentes, visando sanar antigos gargalos decorrentes da intensificação de interações espaciais na região.

Dessa forma, nos planos de integração destinados à escala continental, assim como os destinados ao Cone Sul, prevalece a necessidade de expandir a capacidade das rodovias e da consolidação de um sistema multimodal de transporte. Porém, grande parte dos projetos trata geralmente da otimização de rodovias, estratégia necessária, mas que encontra seu limite em médio prazo, uma vez que a ascensão do fluxo de commodities na região exige uma matriz de transporte mais equilibrada.

Tal fato ocorre especialmente nas obras de melhoria, como a duplicação da rota 14 , a adequação do corredor rio Branco-Montevidéu-Colônia-Nueva Palmira e a Duplicação do Tramo Palhoça-Osório (BR-101) os quais se apresentam como grandes eixos rodoviários nos quais confluem fluxos de mercadorias destinadas ao mercado exterior, mas também ao nacional, regional e, sobretudo, intraurbano, uma vez que, muitas cidades estruturaram-se no entorno desses eixos responsáveis por intensos fluxos pendulares.

Já em menor número, outros projetos devem implantar novos fixos no território, como é caso do Gasoduto do Nordeste Argentino (GNEA), que instalará $4.131 \mathrm{~km}$ de gasodutos no território argentino, possibilitando uma nova fonte de energía para aproximadamente 378.000 usuários (IIRSA, 2012). Nesse mesmo sentido, salienta-se o Transporte Multimodal no Sistema Laguna Merín e Lagoa dos Patos que estabelecerá um novo uso aos sistemas lagunares, que poderá concorrer na região com o modal rodoviário e portuário, gerando ganhos para o sistema de transporte como um todo.

Após pontuar as obras delimitadas como prioritárias na AIC/API, deve-se prosseguir a investigação para se aproximar realmente da compreensão das possíveis repercussões dos projetos da IIRSA/ COSIPLAN para a região do Cone Sul. Dessa maneira, torna-se pertinente avaliar as obras no EID MERCOSUL-Chile definidas no Portfólio da IIRSA e do COSIPLAN.

\section{AS OBRAS NO EID MERCOSUL-CHILE DEFINIDAS NO PORTFÓLIO DA IIRSA/ COSIPLAN}

A maioria das análises acadêmicas realizadas acerca da IIRSA/COSIPLAN foi pautada na agenda de projetos AIC e API. Como salientamos, tal escolha é razoável, uma vez que se trata geralmente de grandes projetos determinados como estratégicos para promover a integração regional. Mas, para compreender a amplitude das intervenções da iniciativa nos países do Cone Sul, torna-se oportuno realizar algumas considerações a respeito dos projetos definidos no Portfólio da IIRSA e do COSIPLAN, com destaque ao EID MERCOSUL-Chile.

Este foi inicialmente dividido em seis Grupos de Trabalho que ficaram responsáveis pela elaboração de projetos que compuseram o EID em questão, como poderemos verificar adiante. Destacam-se, assim, cinco grupos de infraestruturas de transporte: G1, Belo Horizonte - Fronteira Argentina/ BrasilBuenos Aires; G2, Porto Alegre - Limite Argentina/ Uruguai - Buenos Aires; G3, Valparaíso - Buenos Aires; G4, Coquimbo - Região Central Argentina e Paysandú; G6, Pehuenche; e, por fim, o G5, Grupo Energético (Vide Figura 1). 
Figura 1: Delimitação dos Grupos de Trabalho do EID MERCOSUL-Chile.

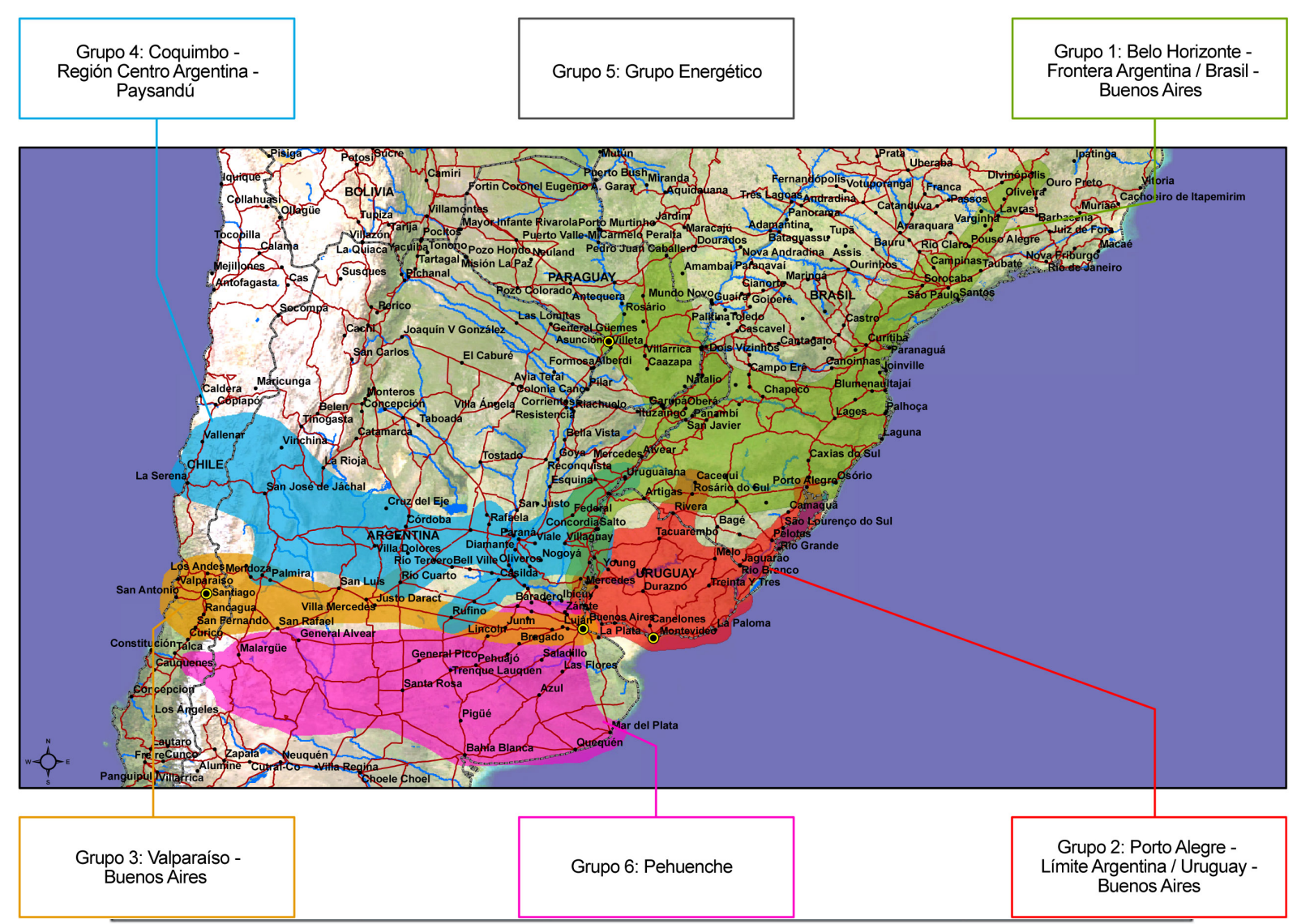

Fonte: IIRSA, 2007. Nota: O Grupo 5, por tratar-se de um projeto transversal, abarca todos os grupos

-G1: Belo Horizonte - Fronteira Argentina/ Brasil-Buenos Aires: nesse grupo, o projeto principal foi a Duplicação da Rota 14 entre Paso de Los Libres y Galeguachu, a partir do qual foram estruturados outros novos projetos, como a duplicação da BR- 381 que liga Belo Horizonte a São Paulo, a recuperação e adequação de portos, ampliação dos aeroportos de Campinas e Guarulhos, entre outros.

-G2: Porto Alegre - Limite Argentina/ Uruguai - Buenos Aires: concentrou-se em grande parte no Uruguai com projetos estruturados em torno da Adequação do corredor Rio Branco - Montevidéu Colonia - Nueva Palmira (Rotas 1,11,8,17,18 e 21) dos quais destacam-se a readequação de portos, a construção de novas pontes com o Brasil e com a Argentina, além dos projetos incorporados à API do COSIPLAN, como o Sistema Lagoa Merín - Lagoa dos Patos.

- G3: Valparaíso-Buenos Aires: visa melhorar o corredor Cristo Redentor, que é a principal rota de transporte entre Argentina e Chile, além da adequação do Posto de fronteira Pehuenche enquanto possível alternativa ao posto de fronteira aduaneiro Cristo Redentor. No entanto, o projeto principal almeja reativar a ferrovia Transandina Central que liga Mendoza a Valparaiso, a qual está parada desde a década de 1990. Entre tais projetos estão inclusos outros de pavimentação, recapeamento e duplicação de rodovias, visando maior fluidez para essas rotas. Partes desses projetos futuramente compuseram um novo grupo de trabalho criado a pedido da Argentina, o G6 Pehuenche, cujo projeto principal foi a readequação do posto de fronteira aduaneiro Pehuenche, que deverá tornar-se alternativa de conexão à porção sul da Argentina e Chile.

· G4: Coquimbo - Região Central Argentina e Paysandú tem grande parte dos projetos designados em território argentino. Os mesmos foram estruturados em torno da reconstrução/ampliação 
da Rota Nacional 168 e do túnel subfluvial entre as cidades de Paraná e Santa Fé, com grande parte dos projetos ligados à pavimentação, duplicação e construção de novas pontes nessa rota.

- G5: Equipe destinada ao setor energético, com enfoque nos projetos de energia elétrica (ampliação da geração de energia em plantas existentes) e gás (projetos de gasodutos).

No ano de 2003, momento em que foi definido o Portfólio de obras da IIRSA, o EID MERCOSUL-Chile apresentava cerca de 68 projetos com investimentos iniciais de US\$12.076 milhões. Por conseguinte, no ano de 2010, os projetos tornaram-se 107 com recursos estimados em US\$ 35.836 milhões, sendo o EID com maior número de projetos $20,3 \%$ e o maior percentual de investimentos 37,3\%. Já com a passagem da IIRSA para COSIPLAN e a reformulação do Portfólio, o mesmo teve seu total de obras reduzido para 105, em contrapartida os investimentos foram elevados para US\$ 44.389,8 milhões (Vide Tabela 4).

Tabela 4: Evolução do número de projetos e investimentos no Portfólio de Projetos da IIRSA e da COSIPLAN para o EID MERCOSUL-Chile para o período de 2003 a 2011(em unidades e milhões de US\$).

\begin{tabular}{|l|c|c|}
\hline Período & $\mathbf{N}^{\mathbf{0}}$ de Projetos & Investimento \\
\hline $\mathbf{2 0 0 3 - 2 0 0 4}$ & 68 & 12.076 \\
\hline $\mathbf{2 0 0 5 - 2 0 0 6}$ & 71 & 12.161 \\
\hline $\mathbf{2 0 0 7}$ & 91 & 19.465 \\
\hline $\mathbf{2 0 0 8 - 2 0 0 9}$ & 105 & 29.399 \\
\hline $\mathbf{2 0 1 0}$ & 107 & 35.836 \\
\hline $\mathbf{2 0 1 1}$ & 105 & $44.389,8$ \\
\hline
\end{tabular}

Fontes: IIRSA- 10 anos depois: Suas conquistas e desafios, 2011; COSIPLAN: Agenda de Projetos Prioritários de Integração, 2011.

Nota: Os valores de "Número de Projetos" e de "Investimentos Estimados" mencionados não incluem os projetos do PSI de TICs, incorporados em finais de 2004 na AIC.

Seguindo o padrão identificado nas obras do Portfólio para todo continente, o setor de transporte apresentou o maior número de projetos. Estes, por sua vez, foram distribuídos sem grandes discrepâncias entre os grupos de trabalho, exceto no caso do Grupo Pehuenche, que contempla o sul da Argentina e do Chile, região que devido à baixa densidade populacional e dinâmica econômica vem sendo preterida historicamente pelos investimentos públicos.

Em contrapartida, os montantes de investimentos estiveram mais concentrados no Grupo Energético Argentina-Uruguai-ParaguaiBrasil, embora possua um número menor de projetos em relação aos demais grupos. Isso ocorre devido ao padrão de obras destinado ao setor de transporte, que, geralmente, trata-se de obras de readequação ou ampliação da capacidade das infraestruturas existentes. Já os investimentos no setor energético têm, principalmente na construção de novas hidroelétricas e na adequação de microcentrais, uma elevada demanda por investimentos (Vide Tabela 5). 
Tabela 5: Discriminação dos projetos do Portfólio da IIRSA 2010 e do COSIPLAN 2011, para o EID MERCOSUL-Chile (em milhões de US\$).

\begin{tabular}{|c|c|c|c|c|}
\hline \multirow{2}{*}{ SETOR } & \multicolumn{2}{|c|}{2010} & \multicolumn{2}{|c|}{2011} \\
\hline & $\mathrm{N}^{\mathrm{o}}$ & Valor & $\mathrm{N}^{\mathrm{o}}$ & Valor \\
\hline \multicolumn{5}{|l|}{ Rodoviário } \\
\hline Ampliação da capacidade & 17 & $4.903,1$ & 15 & $5.191,0$ \\
\hline Reabilitação de calçadas e estruturas & 15 & $1.043,4$ & 14 & $1.025,4$ \\
\hline Pavimentação de obra nova & 7 & 746,0 & 8 & 781,0 \\
\hline Pontes novas e reabilitação & 4 & 158,3 & 5 & 188,3 \\
\hline Circunvalação rodoviária e acesso à cidade & 3 & $2.865,0$ & 4 & $6.045,5$ \\
\hline Túneis novos e reabilitação & 1 & 800,0 & 2 & 1850,0 \\
\hline Manutenção de estradas & 2 & 7,0 & 00 & 00 \\
\hline Total & 49 & $10.522,8$ & 48 & $15.081,2$ \\
\hline \multicolumn{5}{|l|}{ Ferroviário } \\
\hline Construção de Ferrovias & 1 & 100,0 & 1 & 100 \\
\hline Reabilitação de Ferrovias & 9 & $5.684,3$ & 8 & $5.708,0$ \\
\hline Total & 10 & $5.784,3$ & 9 & $5.808,0$ \\
\hline \multicolumn{5}{|l|}{ Fluvial } \\
\hline Construção de novos portos fluviais & 1 & 100,0 & 1 & 100,0 \\
\hline Adequação de portos existentes fluviais & 2 & 56,0 & 2 & 56,0 \\
\hline Total & 3 & 156,0 & 3 & 156,0 \\
\hline \multicolumn{5}{|l|}{ Marítimo } \\
\hline Novos Portos Marítimos & 1 & 35,0 & 00 & 00 \\
\hline Ampliação da infraestrutura terrestre de portos marítimos & 8 & 986,6 & 8 & $1.577,1$ \\
\hline Adequação de portos marítimos & 1 & 375,0 & 1 & 375,0 \\
\hline Total & 10 & $1.396,6$ & 9 & $1.952,1$ \\
\hline \multicolumn{5}{|l|}{ Aéreo } \\
\hline Adequação dos Aeroportos & 1 & 0.0 & 1 & 00 \\
\hline Novos Aeroportos & 1 & 25,0 & 2 & 70,0 \\
\hline Ampliação de aeroportos & 5 & $2.199,3$ & 6 & $2.679,3$ \\
\hline Total & 7 & $2.224,3$ & 9 & $2.749,3$ \\
\hline \multicolumn{5}{|l|}{ Multimodal } \\
\hline Total & 4 & 70,3 & 2 & 25,3 \\
\hline \multicolumn{5}{|l|}{ Postos de fronteira } \\
\hline Infraestrutura para implantação de centros de controle fronteiriço & 4 & 45,0 & 4 & 20,0 \\
\hline Adequação de infraestrutura existente em centros de controle fronteiriço & 1 & 0,8 & 1 & 0,8 \\
\hline Ampliação de infraestrutura capacidade de centros de controle fronteiriço & 2 & 17,0 & 2 & 17,0 \\
\hline Total & 7 & 62,8 & 7 & 37,8 \\
\hline \multicolumn{5}{|l|}{ Energéticos } \\
\hline Hidroelétricas novas e adequação microcentral & 5 & $7.160,0$ & 6 & $10.662,0$ \\
\hline Termoelétrica & 2 & 870,0 & 2 & 670,0 \\
\hline Geração com energia nuclear & 2 & $1.740,0$ & 2 & 1740,0 \\
\hline Outras infraestruturas energéticas & 2 & $1.350,0$ & 2 & 1.010 .0 \\
\hline Construção de novas interconexões energéticas & 6 & $4.499,1$ & 6 & $4.498,1$ \\
\hline Total & 11 & $11.120,0$ & 18 & $185.80,1$ \\
\hline Total Geral & & 35.836 & & $44.389,8$ \\
\hline
\end{tabular}

Fonte: IIRSA. Planificacion Territorial Indicativa: Cartera de Proyectos 2010; COSIPLAN:

Cartera de Proyectos del COSIPLAN 2011. 
Logo, entre os principais impactos ambicionados com os investimentos em obras de infraestruturas no MERCOSUL, destaca-se a intensificação das interações espaciais entre os núcleos urbanos de distintos tamanhos que se encontram distribuídos no decorrer das rodovias, facilitando transações entre os diversos municípios que compõem a rede urbana regional. $\mathrm{E}$, assim, consecutivamente, a inclusão no circuito do capital de municípios pouco abrangidos até o momento, pode vir a servir de ponto de apoio para a conformação de novas cadeias de produção, possibilitando o desenvolvimento de novas áreas produtivas e a sucessiva desconcentração do emprego para estas localidades (IIRSA, 2007).

\section{CONSIDERAÇÕES FINAIS}

O MERCOSUL apresenta sua gênese nas relações bilaterais entre Argentina e Brasil, visando ampliar a complementaridade entre as duas economias. A partir do início da década de 1990, com a consolidação do bloco, foram inseridos Uruguai, Paraguai e, no ano de 2012, a Venezuela, concomitantemente outros países tornaram-se associados como Chile (1996), Peru (2003), Colômbia, Equador (2004), Guiana, Suriname (2013) e Bolívia, este último que se encontra em processo de adesão, estabelecendo um importante mercado para as economias menores que futuramente teriam no bloco seu principal mercado. Mesmo o Brasil, que apresenta grande diversidade de parceiros comerciais, tem importante parcela das exportações originadas no setor industrial brasileiro, destinadas aos países do bloco.

Essa complementaridade econômica decorrente do Mercosul resultou na maior dinâmica comercial no/do continente, intrarregional e extrarregional, conjuntura que torna os problemas referentes à reduzida qualidade e densidade das infraestruturas mais evidentes. Ademais, não foi por acaso que nas últimas décadas os governantes realizaram diversos planos no intuito de ampliar a rede de transporte da região, embora sem lograr sucesso. Dessa maneira, tais demandas por infraestrutura negligenciadas por anos em uma região em que o comércio internacional apresenta contínuo crescimento parecem contribuir para elucidar o fato da área atualmente concentrar obras e investimentos definidos nas Agendas AIC/ API e Portfólios da IRSA/COSIPLAN.

Apesar da proximidade dos portos do Sul do Brasil com os países do MERCOSUL, este mercado representa uma parcela pequena do total importado e exportado pelos portos brasileiros, nos quais ocorre o predomínio do comércio com a América do Norte, Europa Ocidental, Oriente Médio, Japão e China. Sendo assim, parte do comércio, por exemplo, de Santa Catarina e do Rio Grande do Sul com os países do MERCOSUL é realizado, principalmente, pelo modal rodoviário, devido à possibilidade do transporte "porta a porta" (FELIPE JUNIOR, 2012).

Os armadores valorizam distâncias maiores, além disso, as normas e as tributações para a cabotagem são bastante significativas, fator esse que torna mais rápido e barato transportar mercadorias entre o Estado de Santa Catarina (BR) para Argentina ou Uruguai pelo modal rodoviário. Assim, além da ampliação/readequação das infraestruturas, cabe aos países do MERCOSUL buscarem também modernizar o sistema de normas e tributações para circulação de mercadorias no âmbito do bloco.

Indubitavelmente, a retomada da promoção da integração territorial decorrente da IIRSA/COSIPLAN, sobretudo por meio do EID MERCOSUL- Chile, ainda que existam outros eixos que compreendem a região do Cone Sul, apresenta saldos positivos. Esse EID trata de um interessante recorte territorial para distribuição de investimentos em infraestruturas, pois amplia a fluidez territorial, principalmente, entre Argentina, Brasil, Uruguai e Chile, embora os interesses brasileiros, argentinos e uruguaios não estejam exclusivamente voltados para o acesso ao mercado chileno, mas também aos mercados asiáticos por meio dos portos chilenos.

A maioria dos investimentos no EID foi direcionada para áreas que podem ser consideradas dinâmicas economicamente, como é o caso do corredor conformado por Belo Horizonte, São Paulo, Curitiba, Florianópolis, Montevidéu, Buenos Aires, Mendoza, Santiago do Chile e Valparaíso, linha que compõe os pontos nodais da região, já presentes em alguns planos de integração com enfoque territorial, elaborados a partir da década de 1970. Situação que reflete a tendência à "seletividade do capital", em sua 
constante busca por ampliar as "condições gerais de produção" de determinadas áreas em detrimento de outras.

Além disso, considerável parcela dos investimentos foi encaminhada ao setor de transporte, porém, ainda que exista uma intenção em promover uma matriz de transporte equilibrada, foi o modal rodoviário que canalizou a maior parcela dos investimentos. Essas rodovias são lócus de uma confluência de fluxos, pois, além de viabilizar interações espaciais internacionais e regionais, apresentam, em determinados trechos, o adensamento da urbanização em seu entorno, sendo assim a recuperação/ ampliação dessas rodovias conta com apoio da população, pois resulta na melhoria da mobilidade inter/intra-urbana como se verifica em partes da BR 101 no Brasil, da Rota 7 e 14 na Argentina, Rota 5 no Chile etc.

Logo, os investimentos no modal rodoviário são necessários, uma vez que possibilitam momentaneamente a ampliação da fluidez territorial na região, porém, em longo prazo, caso não se diversifique mais intensamente, os investimentos também para outros modais, perde-se a oportunidade de fomentar com maior vigor uma matriz de transporte mais equilibrada e competitiva, capaz de reduzir efetivamente os custos logísticos na região em médio e longo prazo; visto que a atual concentração e a perspectiva de intensificação do comércio regional, em especial de cargas de commodities em trânsito, poderão contribuir com a futura ineficiência de diversos trechos das rodovias do Cone Sul.

\section{REFERÊNCIAS}

ARROYO, M. Território nacional e mercado externo. Uma leitura do Brasil na virada do século XX. São Paulo: FFLCH/USP, 2001. (Tese de Doutorado em Geografia).

COSIPLAN - Conselho Sul-americano de Infraestrutura e Planejamento. Agenda de Projetos Prioritários de Integração 2011. Disponível em: $<$ http://www.iirsa.org/Page/Detail?menuItemId=33>. Acesso em: 1 de jan. 2012.
COSIPLAN - Conselho Sul-americano de Infraestrutura e Planejamento. Cartera de Proyectos del COSIPLAN 2011. Disponível em: < http://www. iirsa.org/Page/Detail?menuItemId=32>. Acessado em: 1 de jan. 2012.

FELIPE JUNIOR, N. F. O transporte marítimo de cabotagem e longo curso e sua importância para a economia brasileira. 2012. (Tese Doutorado em Geografia) FCT, UNESP, Presidente Prudente. 2012.

IIRSA - Iniciativa para la Integración de la Infraestructura Regional Suramericana. Actualización visión de negocios eje Mercosur-Chile, 2007.

IIRSA - Iniciativa para la Integración de la Infraestructura Regional Suramericana. Informes de la Agenda de Implementación Consensuada 2005. Disponível em: <www.iirsa.org/Page/ Detail?menuItemId=65>. Acesso em: 12 de jun. 2013.

IIRSA - Iniciativa para la Integración de la Infraestructura Regional Suramericana. Informes de la Agenda de Implementación Consensuada 2006. Disponível em: <www.iirsa.org/Page/ Detail?menuItemId=65>. Acesso em: 12 de jun. 2013.

IIRSA - Iniciativa para la Integración de la Infraestructura Regional Suramericana. Informes de la Agenda de Implementación Consensuada 2007. Disponível em: <www.iirsa.org/Page/ Detail?menuItemId=65>. Acesso em: 12 de jun. 2013.

IIRSA - Iniciativa para la Integración de la Infraestructura Regional Suramericana. Informes de la Agenda de Implementación Consensuada 2008. Disponível em: <www.iirsa.org/Page/ Detail?menuItemId=65>. Acesso em: 12 de jun. 2013.

IIRSA - Iniciativa para la Integración de la Infraestructura Regional Suramericana. Informes de la Agenda de Implementación Consensuada 2009. Disponível em: <www.iirsa.org/Page/ Detail?menuItemId=65>. Acesso em: 12 de jun. 2013. 
IIRSA - Iniciativa para la Integración de la Infraestructura Regional Suramericana. Informes de la Agenda de Implementación Consensuada 2010. Disponível em: $<$ www.iirsa.org/Page/Detail?menuItemId $=65>$. Acesso em: 12 de jun. 2013.

IIRSA - Iniciativa para la Integración de la Infraestructura Regional Suramericana. Planejamento Territorial Indicativo: Carteira de Projetos 2009. Disponível em: <http://www10.iadb.org/intal/intalcdi/ pe/2009/04494pt.pdf. $>$. Acesso em: 12 de jun. 2013.

IIRSA - Iniciativa para la Integración de la Infraestructura Regional Suramericana. Planificacion Territorial Indicativa: Cartera de Proyectos 2010. Disponível em: <http://www.iirsa.org/admin_iirsa web/Uploads/Documents/lb10_completo_baja.pdf $>$. Acesso em: 12 de jun. 2013.

IIRSA - Iniciativa para la Integración de la Infraestructura Regional de Suramericana. IIRSA 10 anos depois: Suas conquistas e desafios. Buenos Aires: BID/INTAL, 2011.

LURASCHI, N. H. Diagnóstico del transporte internacional y su infraestructura en América del Sur (DITIAS) Transporte carretero (Mercosur y Chile). ALADI, 2000.

SANT'ANNA, J. A. Integración en el sector de transporte en el Cono Sur: transporte terrrestre. Buenos Aires: BID/INTAL, 1997.

SANTOS, M. Por uma outra globalização: do pensamento único à consciência universal. Rio de Janeiro: BestBolso, 2011.

SILVEIRA, M. R.; COCCO, R. G. Interações espaciais, transporte público e estruturação do espaço urbano. Revista Brasileira de Estudos Urbanos e Regionais. v.12, n.1, p. 63-81, maio 2010.

VALENCIANO, E. O. Proyecto: Red Fundamental de Transporte del Cono Sur. Buenos Aires: BID/ INTAL, 1980.

\section{AGRADECIMENTOS}

Este artigo resulta da dissertação de mestrado Integração territorial na América do Sul: uma análise multiescalar a partir das obras da IIRSA/ COSIPLAN. Agradecemos ao auxílio financeiro do Conselho Nacional de Desenvolvimento Científico e Tecnológico (CNPq) e da Fundação de Amparo à Pesquisa do Estado de São Paulo - FAPESP.

Soc. \& Nat., Uberlândia, 27 (1): 37-52, jan/abr/2015 